\title{
Post-Modernity in Falling Man
}

\author{
Chunyan Qi
}

School of Foreign languages, Jingdezhen Ceremic university, Jngdezhen, Jiangxi 432000

15179860203@163.com

Keywords: Post-modernity; Don DeLillo; Falling Man; Post-modernism; Themes; Techniques

\begin{abstract}
The present paper aims to probe into post-modernity of the novel Falling Man, i.e., to study the novel by employing postmodern theories so as to gain a deeper understanding of the novel and throw some light on the interpretation of post-modernity in literary works especially fiction or novels. As a classic work of post-modernity, post-modernity in Falling Man deserves more studies. The present study is to help us probe into the postmodern themes and writing techniques of DeLillo, not limited in Falling Man, and facilitate our understanding of post-modernity in literary works.
\end{abstract}

\section{Introduction}

Introduction to the Novel. Since the catastrophic events of $9 / 11$ and its aftermath, issues of terrorism have dominated the discourse preoccupations in American literature. Falling Man by Don DeLillo is a story of living through and then tackling with the disastrous effect of the terrorist attacks on the world trade centre in New York on September 11, 2001. DeLillo has described his fiction as being concerned with "living in dangerous times", and in a 2005 interview declared, "Writers must oppose systems. It's important to write against power, corporations, the state, and the whole system of consumption and of debilitating entertainments [...] I think writers, by nature, must oppose things, oppose whatever power tries to impose on us." Falling Man is one of such.

The title of Falling Man refers to the main character, Keith, who survived the terrorist destruction of the World Trade Center but feels disconnected from the world. Even though he reconciled with his wife and had an intimate connection with another survivor, he felt out of touch with the world, as if his life was supposed to be ended but was frustrated by fate in an accident. In this sense, although he was one of the "lucky ones", Keith is still "falling" from his ordeal.

It also refers to the famous photograph of The Falling Man taken by Richard Drew, which shows an unidentified man falling head-first from the burning Towers. His photograph became an iconic representation of the pain and suffering brought about by the attack.

Theoretical Basis. Scholars hold that post-modernity is featured by a cultural diversification and profound interconnection of global society, which is in shortage of any single dominant center of political power, communication, or intellectual production. Other scholars consider postmodernism as son of late capitalism, arguing that present economic and technological conditions have given raise to a media dominated society in which there are only interferential representations with no real original referent. Postmodernism by these scholars puts emphasis on the lack of any firm or objective referent for communication and is often a deep going negative historical development.

The key word in postmodern literature is "absurd".It often writes something seemingly impossible, crazy or absurd. Post-modernity is generally defined as a personal response to a postmodern society, the condition in a society which makes it post-modern or the state of being that is associated with a post-modern society.

Post-modernity is the state or condition of being post-modern--- in reaction to that which is modern, as in post-modern art. The literary critic Fredric Jameson and the geographer David Harvey have identified post-modernity with "late capitalism" or "flexible accumulation", a stage of capitalism following finance capitalism, characterized by highly mobile labor and capital and what Harvey called "time and space compression". It is generally agreed that postmodernism comes from and after modernism as the prefix "post-" signifies "after", while some scholars hold that postmodernism is a continuum and development of modernism and exists in the confinement of modernism. 


\section{Post-modern Themes in Falling Man}

Panic Attacks. Panic attack is a traumatic symptom of intense fear or apprehension of sudden onset accompanied by cognitive symptoms. Cathy Caruth holds that the traumatic impact of an event on the traumatic subjects is not instant, but delayed. Traumatic experience remains permanently in the heart of the subject, expecting to be cognized and expressed. Traumatic experience hidden in the heart is not passively hibernated, but constantly actively makes sudden attacks on the subject by means of nightmare, illusion, flashback and other repeated ways to show its existence. (Caruth 11). This is the so-called panic attack. According to E. Ann Kaplan, effects of trauma fall into three types: fracturing of psychological identity, pervasive sense of menace in daily life, sense of humiliation and deficiency. (Kaplan, E. Ann. Trauma Culture: The Politics of Terror and Loss in Media and Literature. New Brunswick: Rutgers University Press, 2005: 12-13.) The second type is closely connected with panic attacks.

The opening paragraph presents the readers the horrific scene of the 9/11 catastrophe when the Twin Towers got attacked. The very scene arouses in the protagonists, the witnesses as well as the readers, a sense of panic.

"The bomber is blown to bits, ......they get trapped in the body of anyone who's in striking range......months later, they find these little, like, pellets of flesh, human flesh that got driven into the skin. They call this organic shrapnel." (DeLillo 18)." Long after that, when Keith was chatting with his son, the phrase "organic shrapnel" constantly and abruptly burst into his mind which he could trace from nowhere. The phrase caused panic attacks to him and the memory of it became part of his life, invading his life and reminding him of the nightmarish experience, which he could hardly bear and get released.

It is worth mentioning that the terrorists attacked out of panic, as Lianne's mother, Nina mentioned the word "panic" twice in "It's sheer panic. They attack out of panic (DeLillo 30)" and "Panic, this is what drives them (DeLillo 58)." The terrorists' panic comes from American hegemony, totalitarianism and unilateralism and from the fear that the US will dominate and dictate the whole world. Panic does not belong to the victims only, but to the terrorists also.

Despair and Escapism. In a catastrophic event, despair and escapism usually go hand in hand. Despair goes before escapism and leads to escapism. The People magazine said, "Don DeLillo's great success in this novel is his terribly accurate portrait of the emotional emptiness and hazy New Yorkers felt during the weeks and months following the 9/11 attacks....."

As for traumatic subjects of the 9/11 event, the survivors, both Keith and Florence isolated themselves, shut down their emotions and feelings and cut off from the outside world. They just want to lead a monotonous and fixed life so as to escape from the painful memories concerning the tragic event. It is clearly seen that self-isolation is a symptom of despair and escapism. Keith and Florence were perplexed with the negative memories and immersed in the terrorist memory all along. They could no longer fit into the community or see a glimpse of hope for the future.

Another aftermath of the 9/11 terrorist attacks is people's doubts and despair about God. People began to harbor doubts about God in its existence and fairness. People began to show distrust toward and escapism from the God. They didn't believe in God any more. Under the context of terrorism and psychological pressure, people developed a sense of despair toward God. They began to doubt about the existence of the God and even rebel against it. In loneliness and helplessness, people needed a spiritual force which they could depend on. They developed a contradictory psyche: on the one hand, they want to pin their hope on God; on the other hand, they are highly skeptical of the existence and presence of God, the almighty God.

Self-destruction. Self-destruction is the evilest consequence of a traumatic event. Keith's indulgency in poker games and his affairs with Florence, Lianne's emotional explosion, Nina's love with Martin and Justin's over-absorption in his studies and plane-searching are all forms of self-destruction. The disastrous effects of the terrorist event can be clearly seen among the three generations: the panic, sadness, bewilderment, despair, escapism all lead to self-destruction in them. In this sense, we can say, the 9/11 terrorist attacks destroy not only the two tall buildings but also the three generations of the US. The terrorist attacks destroy their body, their heart, their hope and 
their future, and force them to self-destruction.

The idea of death, as revealed in the novel, is an extreme case of self-destruction. Death is prominent in this novel, especially senseless death in relation to terrorist acts. The haunting image of death was ever-present in Keith's mind, as well as in the thoughts of Keith's friends who survived the attack. The terrorists, in DeLillo's interpretation, committed themselves to death for a cause they believed was for the better. In this way, death took on a different meaning. Death became a means to an end.

The above themes in Falling Man are typical of post-modern writing, and these themes are closely tied up with post-modern writing techniques.

\section{Post-modern Linguistic Devices in Falling Man}

Realistic and modernistic writing techniques are no longer suitable to present the postmodern world. In Falling Man, DeLillo employs the linguistic devices of repetition, non-linear narrative, fragmentation and others. The following pages give some space to two of them, namely, repetition and fragmentation.

Repetition. As a rhetorical device repetition has been employed long ago, tracing back to some of the earliest political and literary figures. Repetition is used as a mnemonic device to emphasize points and to create rhythm for special effects. DeLillo, as a skilled writer, uses repetition to the greatest extent and at its mightiest. A witty employment of repetition exerts strong stimuli on the readership, enhances the power and beauty of the language, and creates new contexts.

The repetition of the phrase "organic shrapnel" reminds the readers of the horror of the tragedy and enhances the impact of the event in the readership.

DeLillo repeats the saying "He would tell her about Florence" for as many as eleven times to show the protagonist's hesitation and inner conflict. The repetition reinforces the language, adds the rhythm and the poetic language impacts on the reader's senses.

In Falling Man, the word "Wanted" also appeared for several times which alluded to the historical event outside the text.

The word "God" appeared many times in the novel, as people talked about God, wrote about God and debated on God. God used to be omnipotent and omnipresent: all-powerful in everything, but now, things have changed and shifted to the opposite side: people began to harbor doubts about the existence, presence and might of God, as the Alzheimer patients writing group quoted writing about God: "How could God let this happen? Where was God when this happened?"(DeLillo 205)" Repetition of "God" reveals the impotency of God and the despair and helplessness of the victims, both visible and invisible. It also shows the cruelty of terrorism and its disastrous effects on American people, especially New Yorkers.

Fragmentation. DeLillo does not describe the protagonists' traumatic experience in a linear sequence in accordance with the development of the plot, but connects traumatic memories with real life scenes in different time and space level by using narrative devices as parallel montage and fragmentation. DeLillo purposely separates activities and psychological states of the characters to make them seemingly illogical and messy. The story centers around the 9/11 Event and juxtaposes the stories and psychological activities of various characters to achieve a non-linear narrative. The writer employs an open form of writing model, tries to break the conventional closed writing model, and switches between different real spaces to achieve a unique effect. Let's take the terrorist Hammad for example. The presences of Hammad are completely illogical in that they break conventional space-time concept. The fragmented narrative, however, provides access for the readers to Hammad's inner conflicts and bewilderment. Hammad, used to be an ordinary kind-hearted citizen, turned to be a cold-blooded killer after being brainwashed by terrorist doctrine. It is the chaotic society that makes the tragic character.

\section{Post -modern Narrative Devices in Falling Man}

DeLillo's Falling Man is regarded as postmodern for its form or techniques he employs in plotting 
and structuring, among which, two devices are conspicuous: one is parallel montage, and the other is counter grand narrative.

Parallel Montage. In the context of composing a novel, parallel montage is the presenting of two or more story lines separately and subsequently which converge in a complete plot structure. The story lines or events may occur simultaneously in the same location or occur simultaneously in different locations or even occur in completely different time and space (Oatley 110).

From DeLillo's experience we know that DeLillo was constantly exposed to and influenced by a myriad of experimental or radical art exhibitions, movies, drama and music which naturally and reasonably led to the narrative device of parallel montage in his novels, and Falling Man is a fine example of such. It juxtaposes two story lines of victims, actually two groups of victims, one visible and one invisible: Keith and his circle on the one hand, and Hammad and his accomplice on the other. The two story lines or threads occur in completely different time and space but cohere as one plot. The technique of parallel is to showcase the terror of 9/11 attacks and to make explicit the trauma in peoples' heart. DeLillo intends to remind people of the danger of terrorism and tell people to face up to reality positively and actively rather than negatively and passively. . The two story lines develop separately and independently but move toward one plot implicitly which can be strongly sensed by the readership.

Parallel montage in Falling Man intentionally rejects conventional narrative device: linearity, and presents discontinuity and fragmentation which are typical of postmodern writing and the postmodern age. The story lines of Keith and Hammad are presented as two fragments and the time shuttle from history to the present and move back and forth, and it is up to the readers to piece them together and form one plot and gain an integrated understanding. The discontinuity and fragmentation reminds the readers of the reality of the world we are living in: discontinuous, fragmented, disordered, etc.

Counter Grand Narrative. To some extent, narrative and counter-narrative are to achieve just opposite effects: Narrative sets time and constructs history, while counter-narrative dismantles time and reshapes history. In counter-narrative, the author's intent has a close tie with the final effects of the writing. As a special narrative tactic, counter narrative questions the truth of history and the cause-effect logic of official historiography and subverts and damages traditional narrative models within a certain period of history so as to counter the hegemony of grand narrative. Counter-narrative expresses its intransigence towards traditional narrative through mutation, transition and fracture to highlight the rupture and occasionality of historical texts.

According to DeLillo, this kind of counter-narrative lies in the original terror of people's falling from the Twin Towers with arms linked, and the writer's mission is to endow the crying sky with memory, warmth and meaning. The novel jumps out of the writing model of victim- and aftershock-focus, breaks the way of official narrative and propaganda discourse of mainstream media in the US, integrates real history with fictional events, makes breakthroughs in understanding terrorism. In DeLillo's pen, Hammad is no longer an image of detested extreme terrorist as revealed in official statements and media coverage, but rather a familiar "boy next door" who, at the bottom of his heart, doubts about the so-called jihad and want to lead an ordinary life and to be as normal as others: get married and give birth to kids. DeLillo's description of Hammad distances itself from the vicious image by US government and mass media.

DeLillo's reshaping of the image of terrorists not only reveals that counter-terrorism has become a tool of making political capital and economic profits by the Bush Administration, but also indicate collusive relations between American media and Bush Administration, thus restoring the terrorists' true face.

\section{Conclusion}

As one of the greatest contemporary American novelists who is labeled postmodern, Don DeLillo hit the world once again with his bestseller Falling Man in 2007, at the early age of the new millennium. The novel Falling Man showcases the immense effects of 9/11 terrorist attacks on ordinary American citizens, especially New Yorkers, in their ordinary life, psyche, work, etc. 
The main conclusions are as follows: 1) DeLillo's writing experience has close connection with his work experience as a copywriter at the agency of Ogilvy \& Mather, which is clearly revealed in Falling Man; 2) Among the many post-modernist themes, DeLillo chose some of the most prominent ones for Falling Man, such as panic attacks, despair and escapism, and self-destruction, all of which reveal the disaster the $9 / 11$ terrorist attacks have brought to the people concerned both physically and mentally, and effective cure is to be discovered; 3) DeLillo is a proficient writer of post-modernity skilled in post-modern writing techniques, and employed consciously and unconsciously in Falling Man some of the techniques, such as repetition of words, sentences and structures, fragmentation, parallel montage and counter grand narrative. All these techniques indicate the post-modernity of the novel and help the readers acquire an objective and all-sided comprehension of the novel.

What have been revealed in the paper are preliminary steps and initial results. Post-modernity is a huge concept with multiple interpretations. This adds to the difficulty of understanding the concept and employment of the concept to the analysis of the novel. In the present paper, post-modernity refers to some of the postmodern themes and writing techniques. It excludes interpretations in other fields or areas, such as philosophy, politics, arts, architecture, sociology, etc. A preliminary study as it is, still many things concerning the study of the novel Falling Man from the perspective of post-modernity need our due attention and efforts: 1) the connection between the postmodern themes and the postmodern society needs to be further studied. The connection between the themes and the 9/11 terrorist attacks is obvious, but the connection between the themes and the postmodern society is remained to be worked on and valuable fruits are to come out; 2) There are more writing techniques waiting to be explored. DeLillo employed a myriad of writing techniques in Falling Man, and this present paper only touched upon several of them. Still others are to be explored and expounded. If we study as many techniques as possible, we will gain a relatively extensive understanding about the novel and the writing techniques of DeLillo. 3) DeLillo is a proficient novelist and Falling Man is a representative work of him which has gained much popularity in the US and the world as well. Studies on the novel can be conducted from different perspectives and facets, such as trauma theory, humanistic care, metaphoric use, psychoanalysis, etc. All the researches gather together toward a more comprehensive and objective knowledge of the novel and assist the readers acquire a thorough understanding of the writer. Research is a world of no bounds.

\section{References}

[1] Caruth, Cathy. Unclaimed Experience: Trauma, Narrative and History [M]. Baltimore: The Johns Hopkins University Press, 1996: 11.

[2] DeLillo, Don. Falling Man. New York: Scribner, 2007

[3] Kaplan, E. Ann. Trauma Culture: The Politics of Terror and Loss in Media and Literature[M]. New Brunswick: Rutgers University Press, 2005: 12-13.

[4] Oatley, Keith. Such Stuff as Dreams: The Psychology of Fiction. Hoboken: John Wiley and Sons, 2011: 110. 